

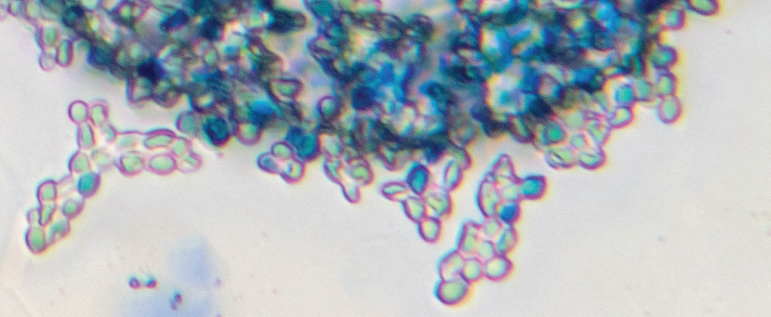

0

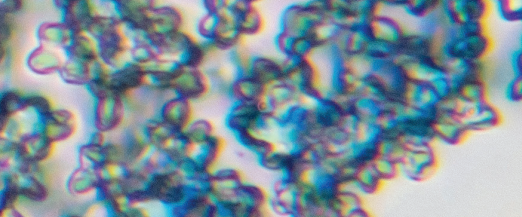

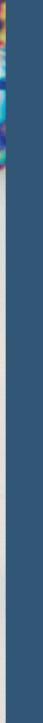

\begin{abstract}
DR FABRIGE GAUDRON
Lecturer in Microbiology

Queen Mary University of London, UK
\end{abstract}

FIELD OF RESEARCH

Cellular and Molecular Biology

\section{RESEARCH PRONEGT}

By experimenting with yeast, Fabrice aims to understand prion-like proteins, how they are used in cell memory and what affect they have on cell ageing.

\section{FUNDER}

Biotechnology and Biological Sciences Research Council

\section{$80+\circ$}

precisely controlled and monitored. It is even possible to change the fluid in the pipes to see how yeast reacts to different conditions, while keeping the cells trapped inside and under a microscope at all times.

\section{HOW DOES YEAST REPRODUCE?}

Normally, a yeast cell reproduces asexually, so there is no need for any 'dating'. A small bud grows from the parent cell, and eventually the two split apart to become separate cells. However, under stressful conditions, yeast can also reproduce sexually. There are two types of mating $S$. cerevisiae, termed type a and type $\alpha$ (alpha). For sexual reproduction, a type a cell needs to meet a type $\alpha$ cell. When a cell wants to mate, it releases pheromones that signal its intent to the other mating type.

The pheromones cause nearby cells of the opposite type to grow a projection towards their potential mate. The distinctive shape of the cell at this stage led to it being named a Shmoo, after a fictional cartoon character by American cartoonist Al Capp. If the two cells touch, they fuse together to mate.

\section{HOW DOES CELL MEMORY WORK?}

The shmooing procedure is not always successful. Fabrice decided to investigate what happens when a cell is exposed to pheromones, but is unable to find a partner or is beaten to it by another cell of the same mating type.

He discovered that cells that are 'deceived' by pheromones remember the experience through a protein named Whi3. When the cell receives the signal but does not find a mate, Whi3 forms a protein aggregate, causing the cell to ignore future pheromone signals. In this way, the cell learns not to make an effort if there is not a good chance of the shmooing process being a success. Instead, the cell will go back to reproducing asexually.

\section{WHY IS FABRICE'S DISCOVERY IMPORTANT?}

Protein aggregation has long been associated with brain diseases like Alzheimer's and Parkinson's. Fabrice's discovery is exciting because it shows that protein aggregates can also be used as a memory mechanism, without harming the cell. In particular, the Whi3 protein aggregate that Fabrice discovered in yeast behaves similarly to a prion, the type of misshaped protein that causes Mad Cow Disease. There is, however, a crucial difference. While prions are passed down through the
This work is supported by the BBSRC under award number BB/S001204/1. The contents of this article are solely the responsibility of the authors and do not necessarily represent the official views of BBSRC.

generations of cells, the memory stored by the Whi3 protein is not inherited by the cell's offspring.

Going forward, Fabrice hopes to build a clearer picture of when prion-like proteins are useful as well as when they cause disease. He aims to observe the process of protein aggregation in zebrafish to test his theories in a multicellular organism. Eventually, if we know how and why protein aggregation occurs in humans, this will help to design new medical treatments for conditions such as Alzheimer's and Parkinson's.

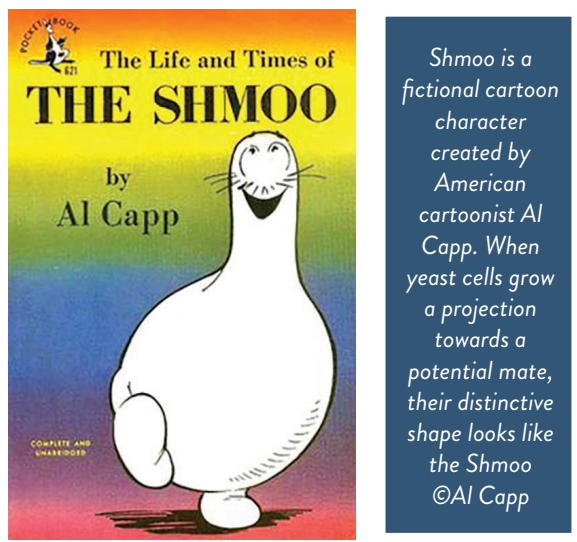




\section{ABOUT GELLULAR AND MOLEGULAR BIOLOGY}

Cells are the basic building blocks of life on Earth. The only living things on our planet that are not made up of cells are viruses (and some scientists do not even class them as living things). That means that the more we know about the inner workings of cells, the better we will understand the biology of all creatures. This is the broad aim of cell biology.

\section{ARE YOU MADE OF CELLS?}

To see how amazing cell biology is, you only need to look in the mirror. Your body is made up of roughly 100 trillion cells! Despite the fact that every single one of your cells has similar biology to the cells that make up a banana, they somehow 'know' how to perform the diverse functions of your different organs.
To manage this, each cell needs to organise its molecules, nanosecond by nanosecond.

\section{HOW ARE MOLECULES}

ORGANISED INSIDE A CELL?

A cell is a bit like a tiny bag filled with a soup of molecules. However, for the molecules to fulfil their functions, the 'soup' needs to be organised so that the right ingredients are in the right place at the right time. So, the matter inside a cell is actually quite structured, albeit in a fluid way that allows the components to move about as required.

The structure of a cell changes depending on the conditions it finds itself in. For example, if a yeast cell growing on a grape were suddenly exposed to the sun on a summer afternoon, it would need to rearrange its molecules to survive. Restructuring also happens when the cell multiplies or, in time, becomes older. This is the kind of thing that cell biologists try to understand through lab experiments.

WHY DO WE NEED CELLULAR AND MOLECULAR BIOLOGISTS?

Do you know of someone who has been ill with meningitis, malaria, diabetes, cancer or cystic fibrosis? These are just some examples of diseases and disorders in humans that are caused by cellular or molecular problems. Even common injuries such as burns and broken bones cause damage to your cells. By understanding how cells work, it is possible to develop new vaccines and search for new medicines.

\section{EXPLORE A GAREER IN GELULAR AND MOLECULAR BIOLOEY}

- The British Society for Cell Biology has an e-learning website where you can discover more about cell biology and training opportunities:

bscb.org/learning-resources/softcell-e-learning/

- Visit the Centre of the Cell in London and check out their youth mentorship scheme: www.centreofthecell.org/

- The average salary for a molecular and cellular biologist in the UK is over $£ 37,000$.

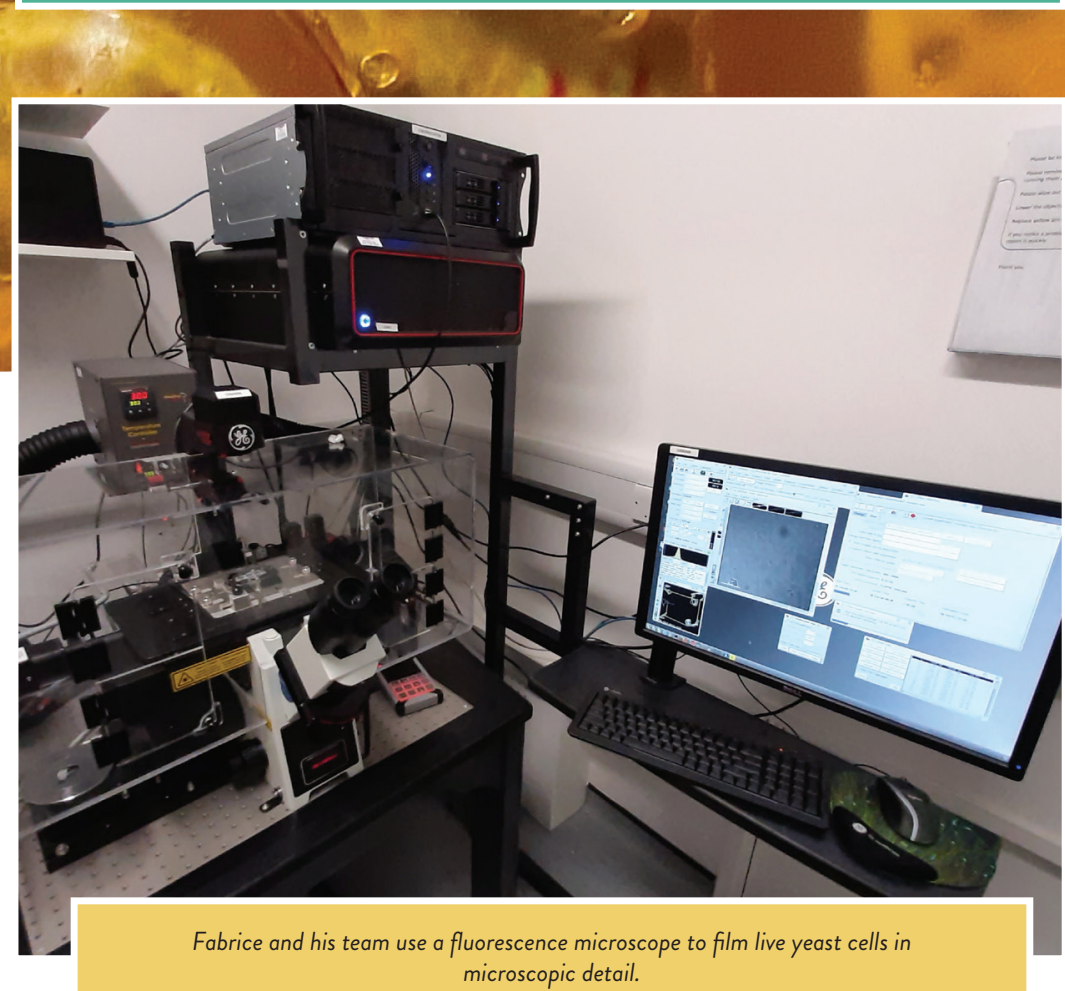

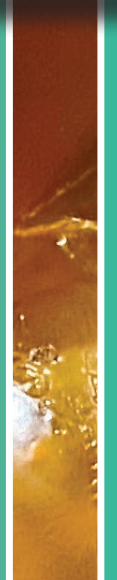

\section{PATHWAY FROM SCHOOL TO GELLULAR AND MOLECULAR BIOLOEY}

Almost everyone working in cellular and molecular biology has a science degree (BSc), and many have a further qualification such as an MSc. Most people in leading roles will have a doctorate (PhD, DPhil, or DSc). However, not all people study biology for their first degree. It is increasingly common for people to transfer from other disciplines such as chemistry and computer science.

If you chose to aim straight for a degree in biology, good school grades in biology and chemistry will probably be required. Selecting physics and maths at school will also make your application stronger. (1) in the

\section{FABRICE'S TOP TIPS}

01 Keep an open mind and have a broad education. Many paths can lead to science, and education is a gift we have, so always try to follow your aspirations.

02 Be passionate and pro-active. You have to find and make the most of opportunities, so try to read either magazines or online content about science.

03 You may need to move a lot during your studies and career: between cities and, if possible, countries. It is important to evaluate if you would be happy with this kind of life and with a job that often requires long days of work. 


\section{. \\ HOW DID FABRICE \\ BECOME A GELLULAR AND MOLECULAR BIOLOEIST?}

WHY WOULD YOU RECOMMEND A CAREER IN CELLULAR AND MOLECULAR BIOLOGY?

Studies in cellular and molecular biology are reaching very deep details of the mechanisms sustaining life, so it is a very satisfying feeling when you make a discovery in this field. There are still so many unknowns in cellular and molecular biology that many researchers will be needed to answer them. At the same time, having a background in cellular and molecular biology does not mean that you must stay in academia - you would have many skills that are valued in industry, such as critical thinking and clear communication.

\section{WHAT DID YOU WANT TO BE WHEN YOU WERE YOUNGER?}

For as long as I remember, I wanted to be a scientist, even though I had very little idea of what it really meant. I think this was driven by our yearly family holidays in the French Alps and the observations of nature this offered. I also remember vividly the first time I looked at cells under a toy microscope. Since then, I wanted to look at cells and this increased more and more during my studies.

\section{YOU HAVE A BSC, MSC AND PHD IN CELLULAR AND MOLECULAR BIOLOGY. WHO OR WHAT INSPIRED YOU TO STUDY THESE FIELDS?}

After high school in France, I engaged in medical studies. For some reason I had developed an aspiration to become a medical doctor. I failed, because the competition was tough and I was only really interested by the molecular and cellular biology lectures. So, I diverted back to biology, and it was much more my thing. I think I chose cell biology because it is the discipline in which I feel most comfortable. Of course, my instinct is very often wrong, but this is part of what makes cell biology interesting!
YOU ARE A BIG FAN OF COMICS AND HAVE USED A COMIC TO CONVEY SOME ASPECTS OF YOUR RESEARCH. DO YOU DRAW COMICS IN YOUR SPARE TIME?

I am not really skilled at drawing, but we did draw a comic for a scientific article recently. It felt fitting because the shape yeast cells adopt when trying to reproduce sexually is called a 'shmoo', and this name comes from the comic book The Shmoo by AI Capp. We just had to adapt our story to it. I would certainly try to do it again, as it is a neat way of conveying a message very simply. There are some artists who create comics and drawings to explain science in a simple and fun way (look at the works of David Goodsell and Beata Mierzwa, for example). But I do not draw in my spare time, I am more inclined to play guitar or train with the local handball team.

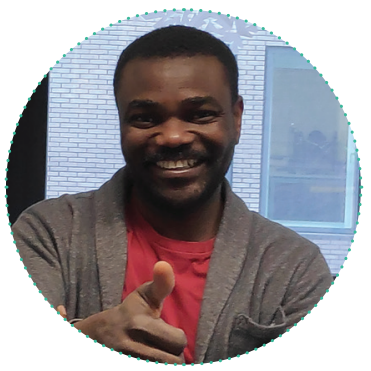

Dr Henry Oamen has joined Fabrice's lab as a postdoctoral research assistant. In academia, this is known as a 'post-doc', and researchers typically spend a few years of their career doing one or more post-docs before securing a permanent role in a university.

\section{Biotechnology was a one of the modules I took while} studying botany at the University of Benin in Nigeria. As I gained more understanding of biotechnology, I became more interested because I realised that through biotechnology, I could modify microorganisms genetically to make useful compounds which will improve our world. This inspired me to pursue a MSc and $\mathrm{PhD}$ in biotechnology.

I became interested in yeast during my $\mathrm{PhD}$. Some of the techniques I applied in biotechnology, such as gene deletions, modifications, protein expression and cloning of genes, have been very useful in my work in Fabrice's lab.

I enjoy being a post-doctoral researcher because it allows me to be at the cutting edge of breakthroughs and to share ideas with other research scientists and the wider community. I enjoy doing experiments and the possibility of discovering something new and interesting that could revolutionise our world.

\section{My top tip for someone hoping to follow in my} footsteps would be to stay focused, inquisitive and bold. I believe in the potential of young people irrespective of race or gender, and I will particularly be happy to see more young black, biological scientists. I think the most important tip for success is to believe in yourself and in your abilities. With this, there is no limit to what you can achieve.

\section{Outside of work, I got involved with Jubilee Charity} while I was studying and living in Manchester. They operate a foodbank, donate to the elderly at Christmas and also assist widows, single mothers and homeless people. I think the number of homeless people on the streets in the UK is alarming. I do recommend Jubilee Charity to anyone willing to be part of community building in Manchester. 